DOI: $10.32481 / \mathrm{djph} .2021 .07 .014$

\title{
A Glance at the Rearview Mirror
}

The Delaware Academy of Medicine/Delaware Public Health Association capped off a most unusual year in customary fashion - it was the same, yet incredibly different.

To look in the rearview mirror a moment: the Academy/DPHA, along with you, rose to the challenge of COVID-19 in perhaps the best way possible. Drawing on our team and collective reserves to never retreat from the threat posed by the virus, but in fact to be better. To be more innovative, more scientific, more empathetic. To insist on compassion and evidence, together. This paid off, with many Delawareans rapidly becoming vaccinated with at least one shot (a cohort which is now over $60 \%$ ). We have done lots of work since the early days of the pandemic - and we have more to do yet.

Our Annual Meeting is more than just a dinner, awards and celebrations. It is equal parts education and collegiality. We have a tradition of bringing a world-class speaker to Delaware; and much as our other scientific conferences in Delaware do, we provide our speakers an engaged, interested audience and the best of the Delaware way of hospitality.

And was this year's keynote speaker ever one to engage his audience! Dr. Geoffrey Tabin, a friend, an ophthalmologist, an adventurer. In his introduction, I spoke of first meeting Geoff at the University of Vermont, of learning about his work with the Himalayan Cataract Project, and of marveling that this amazing individual - a medical celebrity, a curer of blindness - had still resisted the cult of celebrity. Geoff's presentation was a tour de force of culture, history, cataractrelated blindness, resilience, partnership with his mentor and friend Dr. Sanduk Ruit, and of personal journeys. His book, Blind Corners, touches on many parts of this; Oliver Relin's book about this work, titled Second Suns, updates and adds to it. No few words could adequately sum up Dr. Tabin's and Dr. Ruit's work and impact. For that, I ask you to view his TED talks, read the books above, and check out www.cureblindness.org.

The Academy/DPHA Board and staff agreed that, for this unique 2021 meeting, we would follow the best evidence in favor of the safest experience for our attendees. By necessity, this meant double the work for our staff: planning months ahead for an online AND an onsite event. My everlasting gratitude to this amazing team of professionals (Liz Lenz, Kate Smith, and Tim Gibbs primary among them). We were fortunate to partner with a venue that had strict and rigorous meeting rules, in accordance with CDC guidance. We also followed closely all State of Delaware regulations on restrictions, and waited with cautious optimism in hope that the COVID situation in June 2021 would be better, and we would greet each other with 'mask-optional' rather than 'mask-mandatory.'

We also instituted an evidence-based measure which the rest of the US and the media have talked about, but few have implemented: the vaccine passport. Admittedly, we had a great group to work with; in the world of direct healthcare, virtually everyone who is eligible has been vaccinated. We also aim to include all our colleagues, thus we provided an online option for attendees and committed to delivering the same quality of education in that format. Several of you remarked that our system of conference registration/vaccine attestation, paired with on-site high safety and limits on numbers, with our robust online option, blazed the trail for future medical conferences. 
Our guests included the Governor and First Lady of Delaware, and the Lieutenant Governor; healthcare leadership from Delaware, community physicians, Delaware Institute for Medical Education and Research (DIMER) and Delaware Branch Campus students, and health sciences professionals from across the Delaware Valley. It was, literally, a breath of fresh air to interact safely and try out the new normal. To realize that some of our new ways - a bit more physical distancing, enhanced hand hygiene, masking when appropriate - would probably help us indefinitely, whether from novel coronavirus outbreaks or seasonal influenza.

Along with the passing of the torch (or, oversized gavel in our case), each meeting sees a different kind of generational advance: that of our teachers and learners. This is why the Academy/DPHA, in partnership with the Delaware Health Sciences Alliance (www.dhsa.org), emphasizes student engagement. By providing registration for them to our events, we want to model the community of practice that is Delaware healthcare. We remain pleased and proud of these relationships (including with DIMER, the State's medical education program) (figure 1). We are thrilled to send Delaware students to Thomas Jefferson University and the Philadelphia College of Osteopathic Medicine for their basic medical training, and to welcome them back to Delaware for their clinical work - as students, residents, and practicing physicians.

Figure 1. The faces and phases of Delaware medical education. L-R: Kelsey Mellow, MS-3 (PCOM); Dr. Omar Khan; Sherman Townsend, Board Chair of DIMER. 


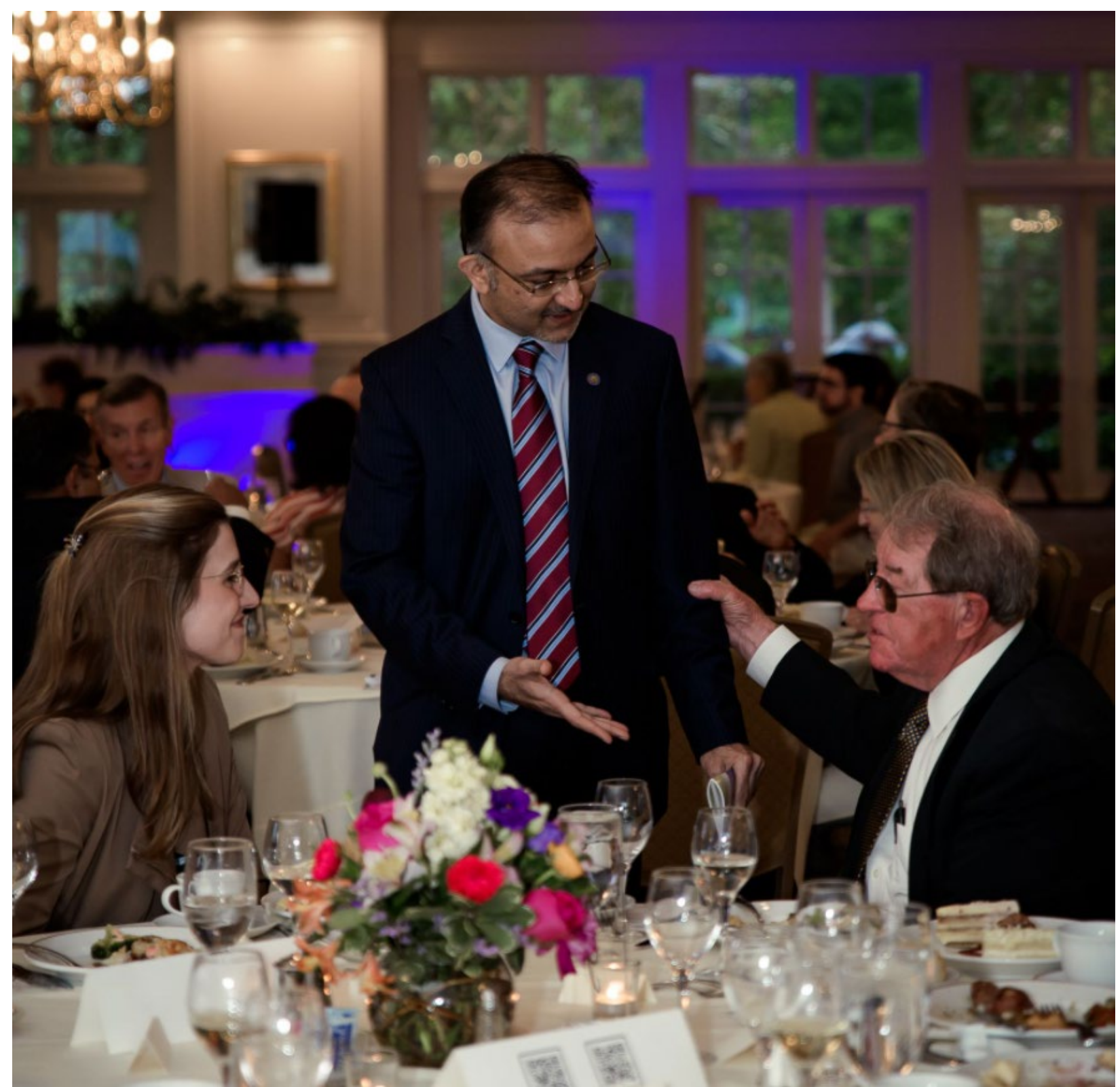

As you peruse the photos and the smiling faces of your friends and colleagues, I ask you to reflect and remember: our country paid too heavy a price these last couple of years. We have thankfully begun to emerge into the light, and for that we have many to thank: all those who were at this unique conference, in one format or another.

For that, and a lot more that has happened and yet to come, we say Thank You, and as always, Drive On!

Omar Khan MD MHS

Immediate Past-President

Chair, Governing Council, DPHA

Editor in Chief, Delaware Journal of Public Health 
DOI: 10.32481/djph.2021.07.014 